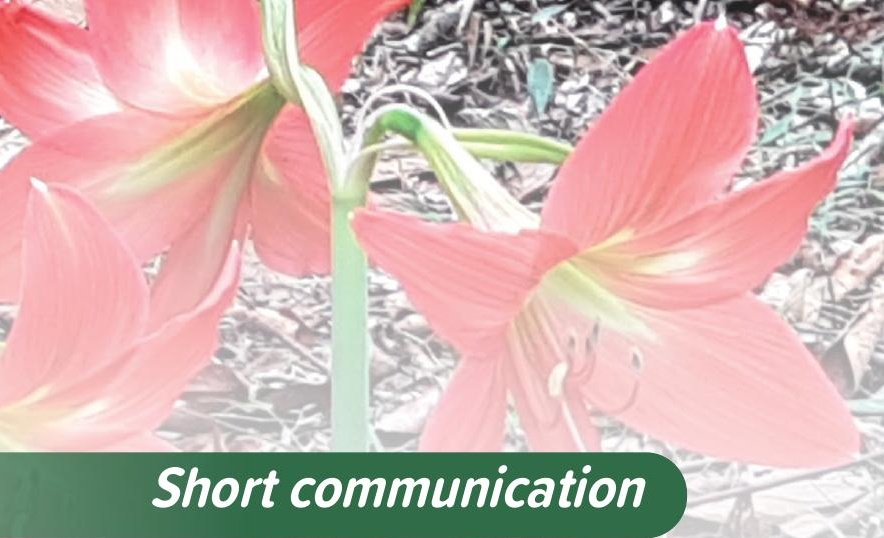

\title{
Testa structure in Erythrina speciosa (Leguminosae): the role of the mucilaginous stratum in the acquisition of physical dormancy
}

\author{
Camila Ribeiro Magalhães ${ }^{1}$ (I) and Denise Maria Trombert Oliveira ${ }^{1 *}$ (1)
}

Received: February 12, 2020

Accepted: July 6, 2020

\begin{abstract}
Seeds of Erythrina speciosa (Papilionoideae) exhibit physical dormancy, but evidence has suggested that the proportion of impermeable seeds increases with storage. There are no records of structural variation in the testa of $E$. speciosa that justifies the difference in the percentage of seeds with physical dormancy. Therefore, the present study investigated the difference in permeability between mature seeds of E. speciosa that were freshly collected and those stored for 12 months. Seeds were examined for changes in testa structure that could result in differences in the percentage of seeds in physical dormancy. Thus, imbibition curves and water gaps were determined, and surface micromorphology, anatomy, and histochemistry of the testa were described. Our results revealed that the proportion of seeds with physical dormancy was higher in stored than in freshly collected seeds, with no anatomical changes in the testa to cause this difference. The analysis of surface micromorphology revealed that, in the lateral region of the seed (the water gap), the mucilaginous stratum was discontinuous in the freshly collected seeds and continuous in stored seeds. These results revealed that the mucilaginous stratum plays an important role in the acquisition and establishment of physical dormancy in E. speciosa.
\end{abstract}

Keywords: anatomy, mucilaginous stratum, physical dormancy, seed coat, structure

Seeds with physical dormancy cannot germinate, although they are viable under adequate environmental conditions, because of the impermeability of the seed/fruit coat to water (Baskin \& Baskin 2014). According to Baskin et al. (2000) and Baskin \& Baskin (2014), impermeability is conferred by one or more layers of the palisade cells, which are impregnated by hydrophobic substances in the seed coat or in the pericarp of indehiscent fruits. The process is widespread among Leguminosae (Rolston 1978;
Werker 1997; Baskin \& Baskin 2014), a family in which seed impermeability is related to the complex anatomy of the testa, which is common to many of its species (Corner 1951; 1976; Gunn 1981). The typical leguminous testa is composed of: an exotesta, formed by a layer of palisade cells; a mesotesta, consisting of hourglass hypodermic cells and some layers of parenchyma cells; and an endotesta, differentiated or not, which can also be composed of hourglass cells (Corner 1951; 1976; Gunn 1981). The

1 Departamento de Botânica, Instituto de Ciências Biológicas, Universidade Federal de Minas Gerais, 31270-901, Belo Horizonte, MG, Brazil

* Corresponding author: dmtoliveira@icb.ufmg.br 
vasculature is commonly restricted to the rapheal bundle, but a post-chalazal extension can occur in certain species. In these species, vasculature extends from the hilum approaching the micropyle, such a way that a bundle runs through the seed from the raphe to the antiraphe (Corner 1976; Gunn 1981).

In many leguminous seeds, an amorphous layer is observed near the outer periclinal face of the cell walls of the exotestal palisade cells (Werker 1997). Many studies refer to this stratum as a cuticle (Corner 1976; ArechavaletaMedina \& Snyder 1981; Ma et al. 2004; Shao et al. 2007; Smýkal et al. 2014; Molizane et al. 2018). However, other studies indicate that it is a mucilaginous stratum (sensu Boesewinkel \& Bouman 1984) because both this layer and the walls of the palisade cells are impregnated with pectic substances (Werker 1997).

According to Delgado et al. (2015), seeds of Erythrina speciosa Andrews (Leguminosae, Papilionoideae) exhibit physical dormancy. However, Molizane et al. (2018) demonstrated that the proportion of seeds in physical dormancy in this species could vary according to parental environmental conditions. According to these authors, in years when there is a higher water deficit during seed formation, only $2 \%$ of produced seeds germinated without scarification. In years with greater availability of water during seed formation, germination reached $40 \%$ without dormancy breaking treatments (Molizane et al. 2018). In addition, Magalhães (2016) observed a difference in the imbibition of $E$. speciosa seeds when analyzed immediately after dispersion and after storage.

Despite the importance of the structure of the impermeable layer in the development of physical dormancy, there is little information regarding the cells that actually exhibit this state. In general, the dormancy is attributed to the palisade cells (Baskin et al. 2000; Baskin \& Baskin 2014). However, Molizane et al. (2018) did not identify anatomical variations in these cells that could cause the difference in permeability between dormant and nondormant seeds. Additionally, Ma et al. (2004) suggested that the difference in permeability in soybean seeds is caused by the presence of small superficial cracks that only occur in the non-dormant seeds. This indicates that the surface of the testa is responsible for seed waterproofing.

Therefore, the goal of this study was to investigate the occurrence of differences in the permeability of the testa of freshly collected mature seeds of E. speciosa and those stored for 12 months by comparing the structure of the seed coat under both conditions. This study proposed that reasons for the differences will be clarified by detailing the surface micromorphology, anatomy, and histochemistry of the testa of freshly collected and stored seeds because physical dormancy is dependent on the structure of the seed coat and its chemical composition.

To accomplish this, ripe fruits at the beginning of natural dehiscence were collected between November and
December 2014 and 2015 from five individuals grown on the campus of the Universidade Federal de Minas Gerais, Belo Horizonte, Brazil (1952'06.2"S-1951'57.8”'S, $\left.43^{\circ} 57^{\prime} 52.2^{\prime \prime} \mathrm{W}-43^{\circ} 57^{\prime} 58.0^{\prime \prime} \mathrm{W}\right)$. The seeds were manually removed from the fruits and analyzed, processed, and stored in the Departamento de Botânica of the Instituto de Ciências Biológicas of the Universidade Federal de Minas Gerais, Belo Horizonte, Brazil. The seeds were separated into two lots of approximately 90 units each, one for analysis immediately after dispersion (freshly collected seeds) and the other for evaluation after 12 months of storage (stored seeds). During the storage period, seeds were packed in paper bags and stored in the shade at room temperature.

To determine the imbibition curves for both freshly collected and stored seeds, three repetitions of 10 randomly selected seeds were weighed and soaked at room temperature environment in Petri dishes with enough distilled water to entirely cover them. At predetermined time intervals (30 min, one, two, three, four, five, six, 12, 18, 48, 72, and $96 \mathrm{~h}$ after time zero), the seeds were weighed, after being dried on a paper towel (Baskin \& Baskin 2014, modified). The measurements were finished when more than $50 \%$ of the seeds had germinated to prevent the seedling weight from altering the result.

To identify the water gap, 10 freshly collected seeds, selected at random, were soaked in a $1 \%$ methylene blue solution for $24 \mathrm{~h}$ (Melo-Pinna et al. 1999). Subsequently, the soaked seeds were manually sectioned with a steel razor along the longitudinal and transversal planes to examine the lateral region (Fig. 1A), hilum, micropyle, chalaza, lens, raphe, and antiraphe (Fig. 1B). Results were documented with a Zeiss ${ }^{\mathrm{TM}}$ Stemi $2000-C$ stereomicroscope with a digital camera attached.

Because they are very hard, before processing for anatomical analysis, the seeds were sectioned using a Dreme $^{\mathrm{TM}} 3000$ micro-rectifier to obtain small samples from the lateral region, hilum, micropyle, chalaza, raphe, and antiraphe. To soften the seed, the samples were placed in $100 \%$ glycerin and heated in a dry VHD ${ }^{\mathrm{TM}} \mathrm{B} 1-\mathrm{AQ} / \mathrm{AG}-$ 100 bath at $100{ }^{\circ} \mathrm{C}$ under agitation for $15 \mathrm{~min}$, followed by gradual cooling for $30 \mathrm{~min}$ at room temperature. The heating-cooling process was repeated four times. After the last repetition, the seeds were washed three times in $95 \%$ ethanol and then kept in this solution for approximately $18 \mathrm{~h}$ to remove all glycerin from the material. The samples did not undergo fixation so that the structure of the testa would not change because of the imbibition of water from the fixative solutions. After softening, the samples were subjected to infiltration and embedding in (2-hydroxyethyl)methacrylate Leica ${ }^{\mathrm{TM}}$ historesin, with freezer processing for 30 days to delay polymerization and optimize the infiltration process (Paiva et al. 2011, modified).

The embedded samples were then sectioned using a Zeiss ${ }^{\mathrm{TM}}$ Hyrax M40 rotary microtome, obtaining longitudinal and transversal sections with a thickness of $10 \mu \mathrm{m}$. The 
sections were stained with $0.05 \%$ toluidine blue in acetate buffer, at a pH of 4.7 (O'Brien et al. 1964, modified), and mounted with Entellan ${ }^{\mathrm{TM}}$. All sections were analyzed under a light microscope and the results were documented with an Olympus ${ }^{\mathrm{TM}}$ U-TV0.5XC-3 or Zeiss ${ }^{\mathrm{TM}}$ Primo Star microscope with a digital camera attached. In addition, the following histochemical tests were performed on transversal sections obtained in the median region of the seeds: ferric chloride plus sodium carbonate to verify the occurrence of phenolic compounds (Johansen 1940); phloroglucinol plus $\mathrm{HCl}$ to identify lignified walls (Sass 1951); ruthenium red for pectin identification (Jensen 1962); and Sudan red for identification of lipids (Brundrett et al. 1991).

To analyze the surface micromorphology, fresh and stored seeds were placed in an oven at $60^{\circ} \mathrm{C}$ for $24 \mathrm{~h}$. They were then fixed on aluminum stubs using epoxy adhesive mass coated with graphite glue. The seed samples were positioned to allow visualization of the lateral region, hilum, micropyle, chalaza, raphe, and antiraphe. The samples were covered with $10 \mathrm{~nm}$ gold in a Balzers ${ }^{\mathrm{TM}}$ SCD 050 apparatus. The surface micromorphology was analyzed using a scanning electron microscope Quanta FEI $^{\mathrm{TM}}$ FEG 3D and digital images were produced.
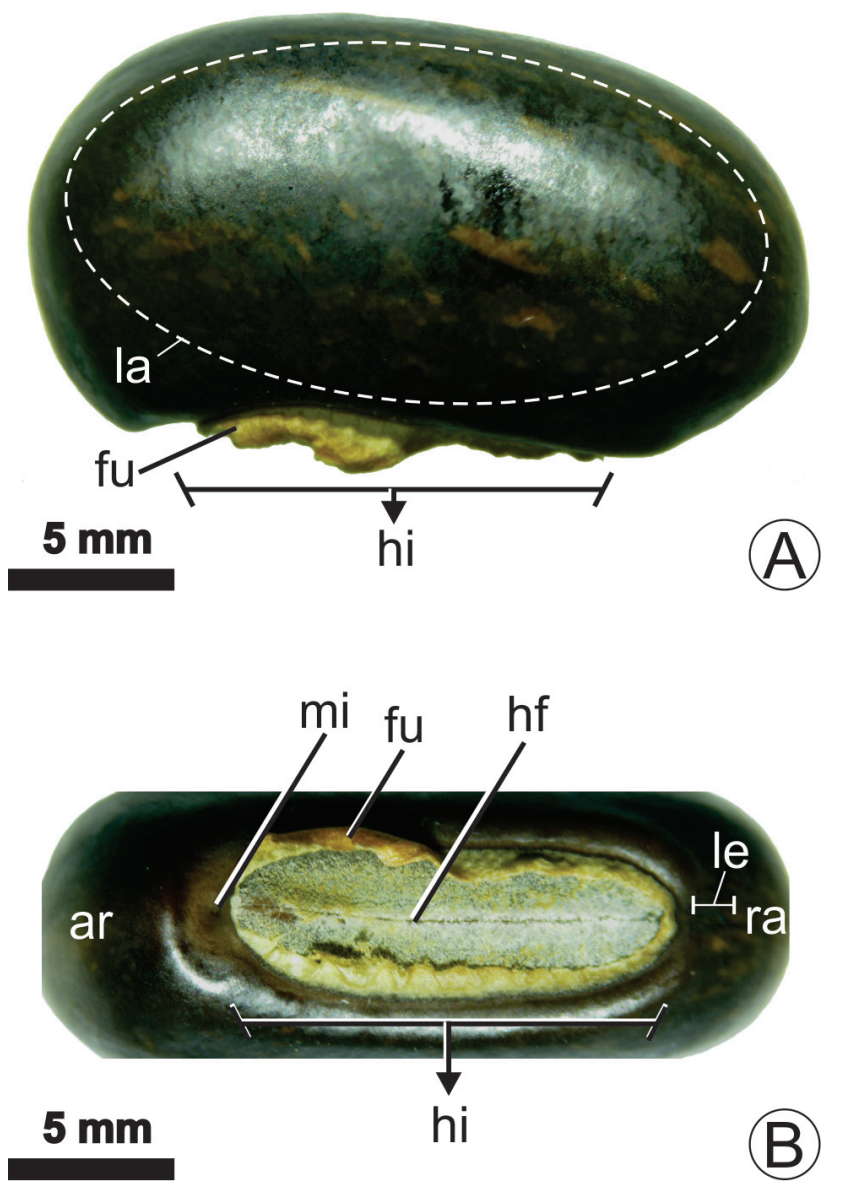

Figure 1. Freshly collected ripe seeds of Erythrina speciosa. (A) Side view. (B) View of the hilum-micropylar region. ar: antiraphe; hf: hilar fissure; fu: funicle residues; hi: hilum; la: lateral region; le, lens; mi: micropyle; ra: raphe.
Our results revealed a difference in testa permeability between freshly collected seeds of E. speciosa and those stored for 12 months. In the freshly collected seeds, after immersion in water for $6 \mathrm{~h}$, an increase in mass because of imbibition was observed, which was intensified after $18 \mathrm{~h}$ of observation (Fig. 2A). In the stored seeds, there was no imbibition at any time during the observation period (Fig. 2B). This difference in permeability could not be explained by the anatomy of the testa because no anatomical differences between the testa of the freshly collected and stored seeds were identified (Fig. 3). Similarly, Molizane et al. (2018) also found no difference in the anatomy of the testa of seeds of E. speciosa when comparing dormant and nondormant seeds.

The testa of E. speciosa is composed of the exotesta, with a layer of palisade cells that is similar in thickness to that of the rest of the testa (Fig. 3A, E). The linea lucida is evident and close to the outer periclinal face of the palisade cells (Fig. 3A, B, E, F). The mesotesta consists of a layer of hourglass cells with spaces among them (Fig. 3A, C, E, G) and a few layers of collapsed parenchyma cells (Fig. 3A, E). In the hilum, an extra layer of palisade cells (the counter palisade) was observed. Together with the palisade layer, the counter palisade delimits the hilar fissure (Fig. 3D, H). Internal to the hilar fissure, the tracheid bar, a longitudinal bar to the hilum and obovate in transversal section, was observed, being formed by tracheids and inserted in a thick strip composed of several layers of spongy-like parenchyma cells (Fig. 3D, H). Histochemical tests exclusively showed lignified walls in the tracheary elements of the rapheal bundle, the only vasculature that occurred in the testa. Phenolic compounds were identified in the cell content both in the exotesta and in the mesotesta. Pectins were located on the cell walls of all layers of the testa, as well as on the mucilaginous stratum (Fig. 3I). The results of the test with Sudan red showed lipids only in a narrow portion peripheral to the mucilaginous stratum (Fig. 3J).

Many studies have related the impermeability of Leguminosae seeds not only to the complex architecture of the testa but also to its outermost layer, known as the cuticle (Corner 1976; Arechavaleta-Medina \& Snyder 1981; Ma et al. 2004; Shao et al. 2007; Smýkal et al. 2014; Molizane et al. 2018). However, according to Werker (1997), the palisade layer and the thin stratum outer to it are typically composed of pectins in leguminous seeds. During the drying process, these pectins undergo chemical changes that make them hard and hydrophobic (Werker 1997). Our results also demonstrated that the stratum outer to palisade of E. speciosa consisted mainly of pectins, with the cutin detected only in a very narrow strip in the outermost layer. Therefore, even with the presence of cutin, we suggest that the mucilaginous stratum (sensu Boesewinkel \& Bouman 1984), because pectins are its main components, is where the impermeability is derived. 
Testa structure in Erythrina speciosa (Leguminosae): the role of the mucilaginous stratum in the acquisition of physical dormancy
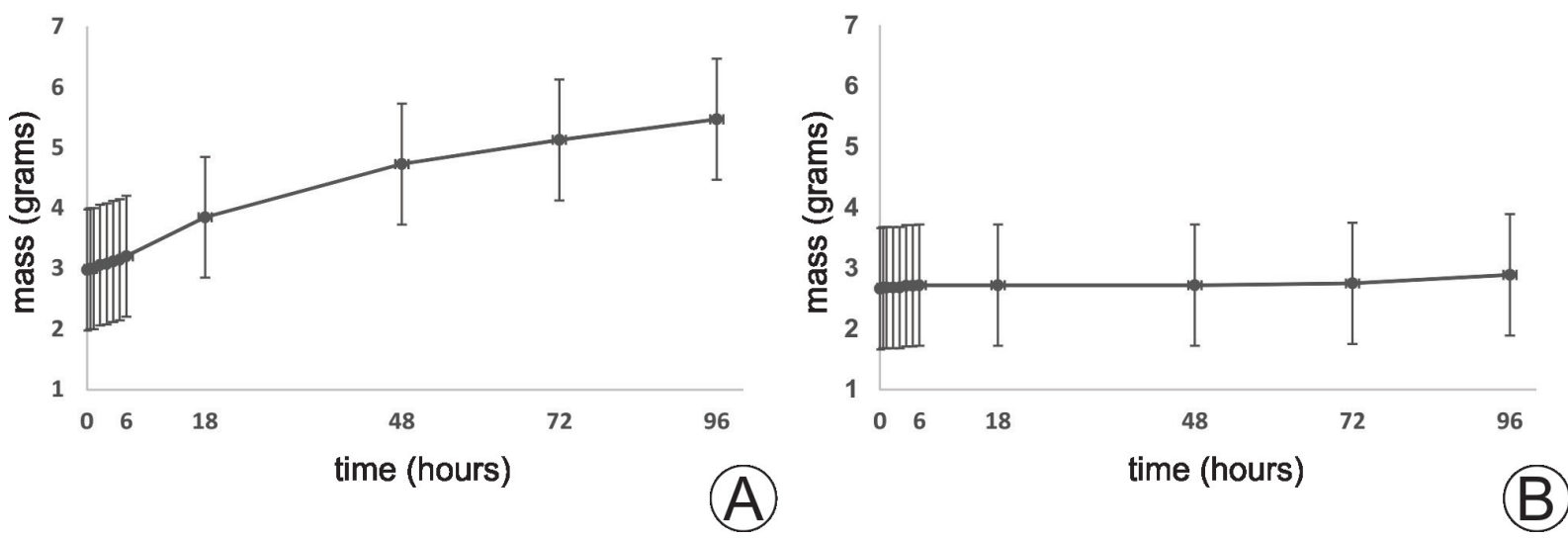

Figure 2. Mass increase of (A) freshly collected seeds, and (B) 12-month stored seeds of Erythrina speciosa during imbibition at room temperature. Error bars are the standard error.

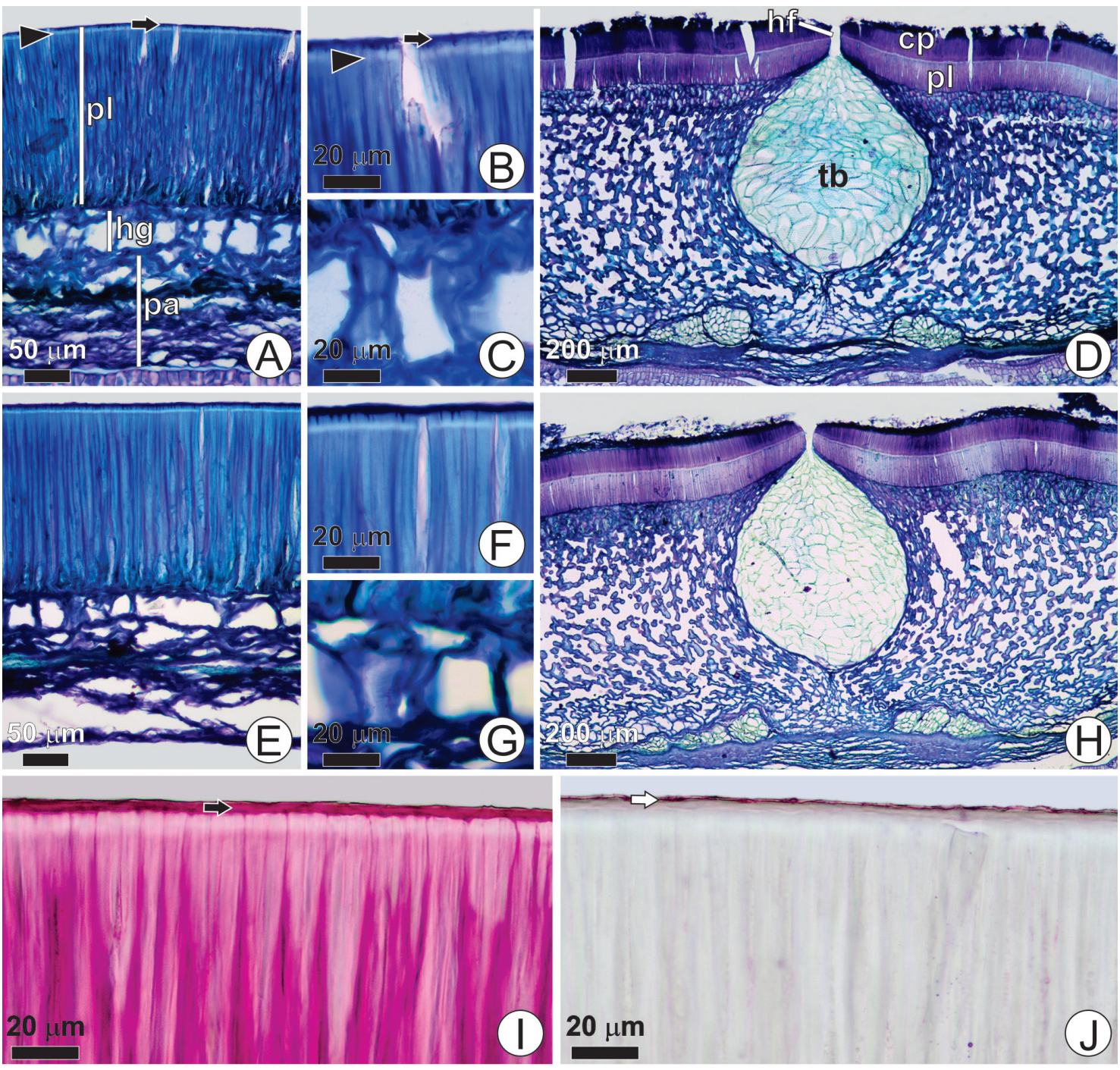

Figure 3. Anatomy of the testa of Erythrina speciosa seeds. Light microscopy of transversal sections. (A-D) Freshly collected seeds. (B-C) Lateral region; in $\mathbf{B}$ and $\mathbf{C}$, details of the exotesta and the hourglass-cell layer, respectively. (D) Hilar region. (E-H) Stored seeds. (E-G) Lateral region; in $\mathbf{F}$ and $\mathbf{G}$, details of the exotesta and the hourglass-cell layer, respectively. (H) Hilar region. (I-J) Histochemical tests. (I) Test with ruthenium red in the lateral region, highlighting the walls with pectic impregnation in pink; note the mucilaginous stratum with intense reaction. (J) Sudan red test in the lateral region showing the presence of lipids only in a thin peripheral layer (white arrow). Black arrow, mucilaginous stratum; arrowhead, linea lucida; cp, counter palisade; hf: hilar fissure; hg, hourglass cells; pa, parenchyma; pl, palisade layer; tb, tracheid bar. 
The surface micromorphology analyses (Fig. 4) revealed that, in the lateral region of the freshly collected seeds, the mucilaginous stratum is discontinuous, presenting a mesh through which it is possible to see the outer periclinal face of many palisade cells of the testa (Fig. 4A). In the stored seeds, the mucilaginous stratum is continuous, covering the entire seed surface (Fig. 4B). The same was observed in the chalazal region (Fig. 4C, D), but with a less conspicuous discontinuous distribution than that in the lateral region of the freshly collected seeds. The openings in the mucilaginous stratum were smaller and more superficial in the chalaza, so the outer periclinal face of the palisade cells is not visible (compare Fig. $4 \mathrm{~A}, \mathrm{C}$ ). In the hilum region of the freshly collected seeds, the surface is formed by several
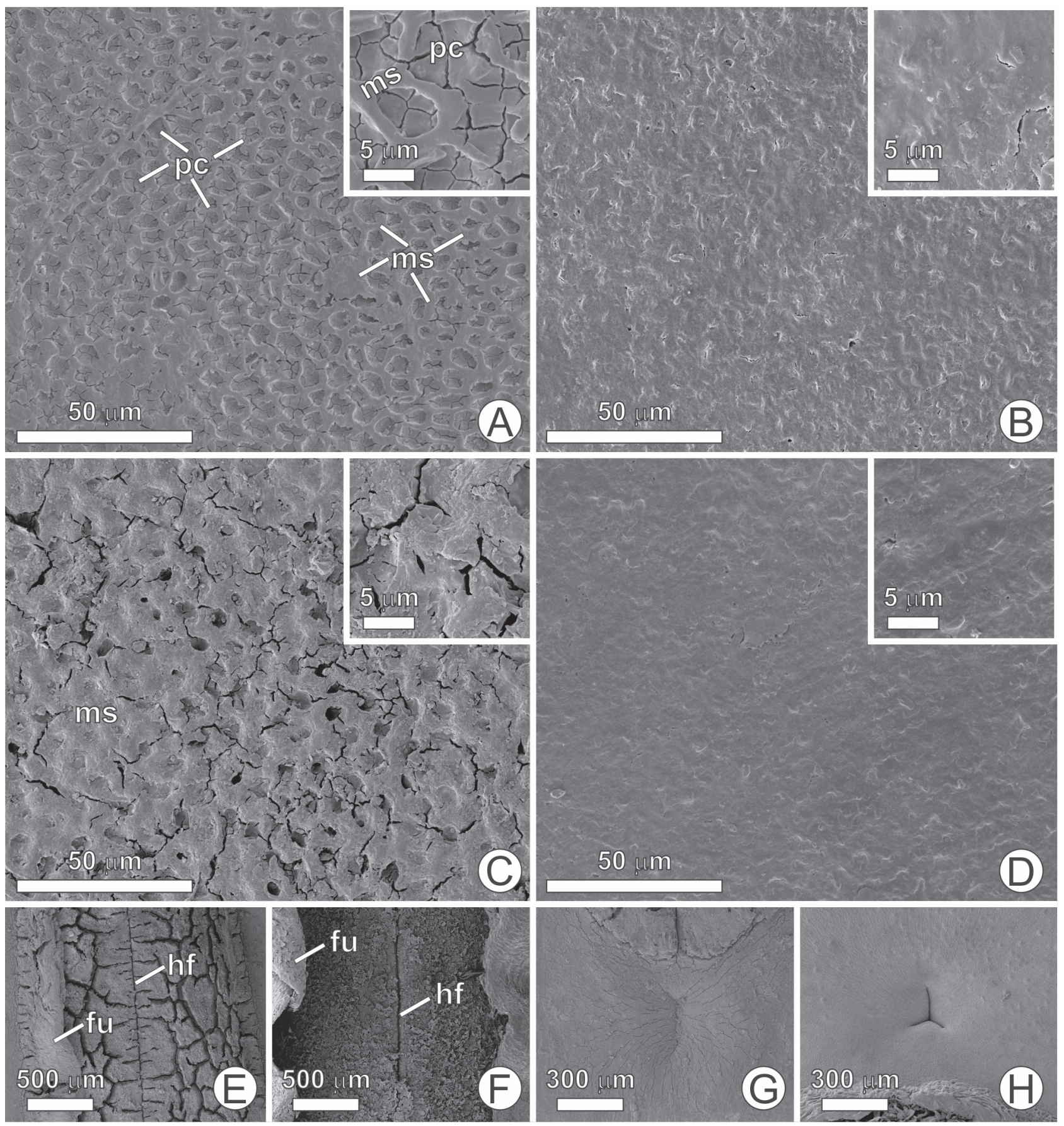

Figure 4. Micromorphology of the surface of Erythrina speciosa seeds as seen with scanning electron microscopy. (A-B) Lateral region of freshly collected seed and stored seed, respectively, with conspicuous outer periclinal face of the palisade cells bordered by the discontinuous mucilaginous stratum. (C-D) Chalazal region of freshly collected seed and stored seed, respectively. (E-F) Details of the hilum of freshly collected seed and stored seed, respectively. (G-H) Details of the micropyle of freshly collected and stored seeds, respectively. fu: funicle residues; hf: hilar fissure; ms, mucilaginous stratum; pc, periclinal face of the palisade cells. 
cracks (Fig. 4E), which are not seen in stored seeds, where the hilar surface is irregular (Fig. 4F). The hilar fissure is quite evident under both conditions (Fig. 4E, F). The micropyle is small and Y-shaped, with a deeper and more evident groove in the stored seeds (Fig. 4H) than in those freshly collected (Fig. 4G). Our results indicated that the difference in permeability between the freshly collected and stored seeds could be attributed to the differences in the conformation of the mucilaginous stratum. In addition, the water gap in the freshly collected seeds is in the lateral region, as evidenced in the soaking test with methylene blue. The blue color laterally permeated all layers of the testa (Fig. 5), indicating the region that the mucilaginous stratum is highly discontinuous.

Molizane et al. (2018) observed that the higher the moisture content in E. speciosa seeds, the higher the germination percentage without any scarification treatment. In other words, the authors suggested that, in E. speciosa, the higher the moisture content, the lower the proportion of seeds with physical dormancy. After dispersion of Papilionoideae seeds, there may be a decrease in moisture content due to hilum activity, because seeds can continue to lose water even after dispersing (Hyde 1954; Baskin \& Baskin 2014). According to Hyde (1954), the Papilionoideae hilum functions as a hygroscopic valve. In the hilum, the counter palisade is external to the exotesta, and both have cells with very thick and pectic walls. These layers facilitate dehydration when the seed experiences a very low relative humidity, with rehydration when the humidity increases again (Baskin \& Baskin 2014). When the counter palisade and the palisade are dehydrated, the walls contract and the hilar fissure opens, allowing the diffusion of water vapor from the inside to the outside of the seed. According to Hyde (1954), this water-loss process occurs whenever the relative humidity of the air decreases.

Although the moisture content was not determined in this study, it is likely that the impermeability of the testa of E. speciosa was directly related to this factor. In this species, the dispersion of seeds occurs during the rainy season, when relative humidity is high. During storage in this study, the seeds experienced lower relative humidity because they remained stored for 12 months and passed through the dry season. Thus, we believe that the moisture content of the seeds decreased and allowed the alteration in the distribution of the mucilaginous stratum of the seeds that had been dispersed and permeable, with the change making them impermeable.

Our results added important information to those reported by Molizane et al. (2018) regarding the physical dormancy of E. speciosa. Molizane et al. (2018) demonstrated that the proportion of seeds with physical dormancy in the species varied according to the percentage of water in the seeds, and the present study showed that changes in the distribution of the mucilaginous stratum were responsible for the increase in the proportion of seeds with physical dormancy after storage. These results revealed the relevance of the mucilaginous stratum for dormancy in E. speciosa, increasing our understanding of how the acquisition and establishment of physical dormancy before and after dispersion in legumes occurs.

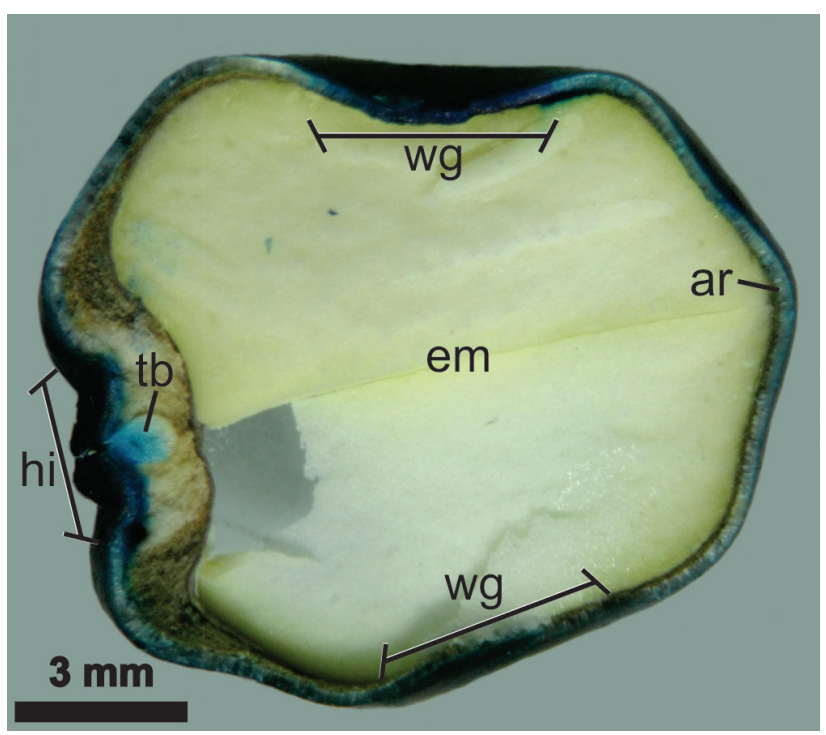

Figure 5. Determination of the water gap in seeds of Erythrina speciosa. Transversal section of a seed soaked with methylene blue. ar, antiraphe; em, embryo; hi, hilum; tb, tracheid bar; wg, water gap.

\section{Acknowledgements}

This study was financed in part by the Coordenação de Aperfeiçoamento de Pessoal de Nível Superior, Brazil (CAPES, Finance Code 001). The authors would like to acknowledge the Centro de Microscopia at the Universidade Federal de Minas Gerais (https://www.microscopia.ufmg. br) for providing the equipment and technical support for experiments involving electron microscopy. We also thank the Brazilian Conselho Nacional de Desenvolvimento Científico e Tecnológico (CNPq) for the research productivity of DMT Oliveira (process 305686/2018-6).

\section{References}

Arechavaleta-Medina F, Snyder HE. 1981. Water imbibition by normal and hard soybeans. Journal of the American Oil Chemists Society 58: 976-979.

Baskin CC, Baskin JM. 2014. Seeds: ecology, biogeography, and evolution of dormancy and germination. 2nd. edn. San Diego, Academic Press.

Baskin JM, Baskin CC, Li X. 2000. Taxonomy, anatomy and evolution of physical dormancy in seeds. Plant Species Biology 15: 139-152.

Boesewinkel FD, Bouman F. 1984. The seed: structure. In: Johri BM. (ed.) Embryology of angiosperms. Berlin, Springer Verlag. p. 567-610.

Brundrett MC, Kendrick B, Peterson CA. 1991. Efficient lipid staining in plant material with sudan red $7 \mathrm{~b}$ or fluoral yellow 088 in polyethylene glycol-glycerol. Biotechnic \& Histochemistry 66: 111-116.

Corner EJH. 1951. The leguminous seed. Phytomorphology 1: 117-150.

Corner EJH. 1976. The seeds of dicotyledons. Cambridge, Cambridge University Press. 
Delgado CML, Paula AS, Santos M, Paulilo MTS. 2015. Dormancy-breaking requirements of Sophora tomentosa and Erythrina speciosa (Fabaceae) seeds. International Journal of Tropical Biology and Conservation 63: 285-294.

Gunn CR. 1981. Seeds of the Leguminosae. In: Polhill RM, Raven PH. (eds.) Advances in legume systematics. Part 2. London, UK, Royal Botanical Gardens Kew, Crown Copyright. p. 913-926.

Hyde EOC. 1954. The function of the hilum in some Papilionaceae in relation to the ripening of the seed and the permeability of the testa. Annals of Botany 18: 241-256.

Jensen WA. 1962. Botanical histochemistry: principles and practice. San Francisco, W.H. Freeman and Company.

Johansen DA. 1940. Plant microtechnique. New York, McGraw-Hill Book Company.

Ma F, Cholewa E, Mohamed T, Peterson CA, Gijzen M. 2004. Cracks in the palisade cuticle of soybean seed coat with their permeability to water. Annals of Botany 94: 213-228.

Magalhães CR. 2016. Estrutura tegumentar de sementes de espécies arbóreas de Leguminosae e sua relação com o armazenamento. MSc Thesis, Universidade Federal de Minas Gerais, Belo Horizonte.

Melo-Pinna GFA, Neiva MSM, Barbosa DCA. 1999. Estrutura do tegumento seminal de quatro espécies de Leguminosae (Caesalpinioideae), ocorrentes numa área de caatinga (PE Brasil). Revista Brasileira de Botânica 22: 375-379.

Molizane DM, Julio PGS, Carmello-Guerreiro SM, Barbedo CJ. 2018. Physical, physiological and anatomical changes in Erythrina speciosa Andrews seeds from different seasons related to the dormancy degree. Journal of Seed Science 40: 331-341.

O’Brien TP, Feder N, McCully ME. 1964. Polychromatic staining of plant cell walls by toluidine blue O. Protoplasma 59: 368-373.

Paiva EAS, Pinho SZ, Oliveira DMT. 2011. Large plant samples: how to process for GMA embedding? Methods in Molecular Biology 689: 37-49.

Rolston MP. 1978. Water impermeable seed dormancy. The Botanical Review 44: 365-396.

Sass JE. 1951. Botanical microtechnique. Ames, Iowa State University Press. Shao S, Meyer CJ, Ma F, Peterson CA, Bernards MA. 2007. The outermost cuticle of soybean seeds: chemical composition and function during imbibition. Journal of Experimental Botany 58: 1071-1082.

Smýkal P, Vernoud V, Blair MW, Soukup A, Thompson RD. 2014. The role of the testa during development and in establishment of dormancy of the legume seed. Frontiers in Plant Science 5: 351.

Werker E. 1997. Seed anatomy. Berlin, Gebrüder Borntraeger. 